\title{
The efficacy of immune checkpoint inhibitors in advanced non-small cell lung cancer harboring driver mutations
}

\author{
HIROAKI SAKAMOTO ${ }^{1}$, HISASHI TANAKA ${ }^{1}$, TOSHIHIRO SHIRATORI ${ }^{1}$, \\ KEISUKE BABA ${ }^{1}$, YOSHIKO ISHIOKA ${ }^{1}$, MASAMICHI ITOGA ${ }^{1}$, KAGEAKI TAIMA ${ }^{1}$, \\ YUKIHIRO HASEGAWA $^{2}$, SHINGO TAKANASHI ${ }^{3}$ and SADATOMO TASAKA ${ }^{1}$ \\ ${ }^{1}$ Department of Respiratory Medicine, Hirosaki University Graduate School of Medicine, Hirosaki, Aomori 036-8562; \\ ${ }^{2}$ Department of Respiratory Medicine, Aomori Prefectural Central Hospital, Aomori 030-8553; \\ ${ }^{3}$ Health Administration Center, Hirosaki University, Hirosaki, Aomori 036-8562, Japan
}

Received September 19, 2018; Accepted March 27, 2019

DOI: $10.3892 /$ mco.2019.1838

\begin{abstract}
The present retrospective study was conducted to evaluate the efficacy of immune checkpoint inhibitors (ICIs) in patients with advanced non-small cell lung cancer (NSCLC) harboring driver mutations. Patients with NSCLC harboring driver mutations who received ICIs (nivolumab or pembrolizumab) were reviewed in Hirosaki University and Aomori Prefectural Central Hospital. There were 139 patients who received molecular targeted drugs, including 24 patients treated with ICIs. Patient characteristics were as follows: Male/female, 5/19; median age 68 (range 39-82); smoking/non-smoking, 6/18; PS 0-1/2, 20/4; driver mutation status, EGFR/ALK/RET/ROS1: 21/1/1/1. The overall response rate was $16.7 \%$ [95\% confidence interval (CI), 7.0-37.1\%] and the disease control rate was $33.4 \%$ (95\% CI, 18.9-55.1\%). The median progression-free survival (PFS) time was 62 days (95\% CI 52-81 days). In the patients who had been treated by the preceding tyrosine kinase inhibitor (TKI) for $>1$ year, the PFS time was 110 days. On the other hand, in the patients who had received a TKI for less than a year, the PFS time was 56 days, which was significantly shorter $(\mathrm{P}=0.012)$. To conclude, some of the patients with NSCLC harboring driver mutation could benefit from ICIs, and the duration of previous TKI treatment may be associated with the efficacy.
\end{abstract}

\section{Introduction}

Lung cancer is the leading cause of cancer-related death in the world, with non-small cell lung cancer (NSCLC) accounting

Correspondence to: Dr Hisashi Tanaka, Department of Respiratory Medicine, Hirosaki University Graduate School of Medicine, 5 Zaifu-cho, Hirosaki, Aomori 036-8562, Japan E-mail: xyghx335@gmail.com

Key words: non-small cell lung cancer, immune checkpoint inhibitors, driver mutation, programmed death ligand-1, tumor mutation burden for $85 \%(1,2)$. Management of advanced NSCLC has changed drastically over the past 15 years. Specific targeted therapies have been available for the treatment of advanced NSCLC. Tyrosine kinase inhibitors (TKIs) for driver mutations such as epidermal growth factor receptor (EGFR) mutations, anaplastic lymphoma kinase (ALK) translocations, and c-ros oncogene 1 (ROS-1) are superior to conventional platinum based cytotoxic agents in clinical trials (3-7). Moreover, immune checkpoint inhibitors (ICIs) which target programmed death-1 (PD-1) and programmed death ligand-1 (PD-L1) have been shown to contribute to overall survival (OS) as first or second line therapy in advanced NSCLC (8-11). However, subset analysis of phase III clinical trials indicated that ICIs might be less effective in advanced NSCLC harboring driver mutations (12). A retrospective study showed that ICIs had progression-free survival (PFS) as short as 1.2-2.1 months in those with EGFR mutations (13). It has been reported that the overall response rate (ORR) was $3.6 \%$ when ICIs were used for the patients with EGFR mutation (14). In addition, a basic research suggested that the expression of PD-L1 in patients with EGFR/ALK wild type is lower than that of patients with EGFR/ALK mutated patients (15). In this study, we analyzed a real world cohort of patients with NSCLC harboring driver mutations who were treated with ICIs.

\section{Patients and methods}

Study design. In this retrospective observational study, we aimed to evaluate the efficacy of ICIs in advanced NSCLC harboring driver mutations. The medical records were collected from two institutions, Hirosaki University (Hirosaki, Japan) and Aomori Prefectural Central Hospital (Aomori, Japan). This study was approved by the Hirosaki University institutional review board and Aomori Prefectural Central Hospital institutional review board.

Target lesion assessment. The efficacy of ICIs was assessed according to Response Evaluation Criteria in Solid Tumors (RECIST), version 1.1. The size of the target lesions were measured by imaging studies (i.e, chest radiography, computed tomography, magnetic resonance imaging). 
Evaluation and statistical analysis. The PFS was estimated using the Kaplan-Meier method. The PFS has been defined as the time from the date of treatment initiation to the date of disease progression, death or the last contact. If neither event was observed, it was considered to be censored with the latest observation date. In case, post-treatment was started, it was considered to be censored with the date of initiation of next line chemotherapy. If the event was unknown in the case of transfer or non-arrival, it was censored with the final date when the patient survival was confirmed. Statistical analyses were performed using JMP 10 (SAS Institute, Cary, NC, USA). Intergroup comparisons of response rate and other parameters were made using the log-rank and chi-square tests. The significance level was set at $\mathrm{P}<0.05$.

\section{Results}

Patient characteristics. Among 139 patients who were treated previously with molecular targeted therapy at Hirosaki University and Aomori Prefectural Central Hospital from September 2014 to January 2017, 24 received ICI. The characteristics of the 24 eligible patients were listed in Table I. Five male (20.8\%) patients and 19 female (79.2\%) patients, with a median age of 68 years (range, 39-82 years), were included. Twenty (83.3\%) patients had Eastern Cooperative Oncology Group (ECOG) performance status (PS) of 0-1, and 23 (95.8\%) had adenocarcinoma histology. Only one patient had squamous cell carcinoma histology. Two patients had stage IIIB, 12 had stage IV, and 10 had recurrent disease. The driver mutation status was as follows: Exon 19 del/exon 21 L858R/ALK/ROS-1/Rearranged during transfection (RET) in 14/7/1/1/1, respectively. The reason for discontinuation of prior TKI treatment for all patients was caused by progressive disease (PD). All patients except one patient who had ROS-1 positive patients received prior molecular target therapy. There were 7 patients $(29.2 \%)$ who had resistant mutation. Twenty two $(91.7 \%)$ patients were treated with nivolumab, 2 (8.3\%) patients were treated with pembrolizumab.

Efficacy. The response to ICIs was shown in Table II. Four patients attained a partial response (PR) but no patients attained a complete response (CR). The ORR was $16.7 \%$, and 4 patients $(16.7 \%)$ had stable disease (SD). Fifteen patients $(62.5 \%)$ had PD. Subset analysis for the ORR by baseline characteristics of patient was shown in Table III. There were no significant relationships between patient characteristics and response to ICIs. No patients $(0 \%)$ with T90M achieved PR. On the other hand, 4 patients $(23.5 \%)$ with negative or unknown of resistance gene achieved $\mathrm{PR}$, although the difference did not reach statistical significance $(\mathrm{P}=0.10)$.

The median PFS was 62 days (95\% CI, 52- 81) (Fig. 1). A significant difference was observed in the PFS between the patients with longer treatment with TKI and those with shorter treatment (110 vs. 56 days; $\mathrm{P}=0.012$; Fig. 2 ). Of the 23 patients who received prior TKI treatment, 9 patients had TKI treatment period of 1 year or more, and the remaining 14 patients had TKI administration period of less than 1 year. One patient who had ROS-1 mutation was not treated with any TKI. There were no significant correlations between other clinical characteristics and PFS. In our study, there
Table I. Patient characteristics $(n=24)$.

\begin{tabular}{|c|c|}
\hline Variable & Number \\
\hline \multicolumn{2}{|l|}{ Sex, n (\%) } \\
\hline Male & $5(20.8)$ \\
\hline Female & $19(79.2)$ \\
\hline Age, years (range) & $68(39-82)$ \\
\hline \multicolumn{2}{|l|}{ ECOG PS, n (\%) } \\
\hline $0-1$ & $20(83.3)$ \\
\hline 2 & $4(16.7)$ \\
\hline \multicolumn{2}{|l|}{ Clinical stage, n (\%) } \\
\hline IIIB & $2(8.3)$ \\
\hline IV & $12(50.0)$ \\
\hline Recurrence & $10(41.7)$ \\
\hline \multicolumn{2}{|l|}{ Histological type, n (\%) } \\
\hline Adenocarcinoma & $23(95.8)$ \\
\hline Squamous cell carcinoma & $1(4.2)$ \\
\hline \multicolumn{2}{|l|}{ Smoking history, n (\%) } \\
\hline Smoker & $6(25.0)$ \\
\hline Non smoker & $18(75.0)$ \\
\hline \multicolumn{2}{|l|}{ Driver mutation, $\mathrm{n}(\%)$} \\
\hline Exon 19 del & $14(58.3)$ \\
\hline Exon $21 \mathrm{~L} 858 \mathrm{R}$ & $7(29.1)$ \\
\hline ALK & $1(4.2)$ \\
\hline ROS-1 & $1(4.2)$ \\
\hline RET & $1(4.2)$ \\
\hline \multicolumn{2}{|l|}{ Resistance gene, n (\%) } \\
\hline T790M positive & $7(29.2)$ \\
\hline Negative or unknown & $17(70.8)$ \\
\hline \multicolumn{2}{|l|}{ Treatment, n (\%) } \\
\hline Nivolumab & $22(91.7)$ \\
\hline Pembrolizumab & $2(8.8)$ \\
\hline
\end{tabular}

ECOG, Eastern Cooperative Oncology Group; PS, performance status; EGFR, epidermal growth factor receptor; ALK, anaplastic lymphoma kinase; ROS-1, c-ros oncogene 1; RET, Rearranged during transfection; T790M, EGFR-T790M mutation.

were 2 patients with rare mutation. One patient had ROS-1 and another patients had RET.

A 71-year old woman was diagnosed with stage IV lung adenocarcinoma with ROS-1 in November 2015. After her four cycles of carboplatin plus pemetrexed followed 4 cycles of maintenance therapy, she had PD. Increased primary tumor and multiple liver metastases appeared. She was treated with nivolumab and on 9 cycles of treatment, a PR was confirmed (Fig. 3).

\section{Discussion}

In this retrospective study, we evaluated that the efficacy of ICIs in patients with advanced NSCLC harboring driver mutations and relationship between the efficacy and the patient characteristics. We found that ORR was $16.7 \%$, which 
Table II. Response to immune checkpoint inhibitors.

\begin{tabular}{lcc}
\hline Response & Number of patients & Percentage, \% \\
\hline Complete response & 0 & 0 \\
Partial response & 4 & 16.7 \\
Stable disease & 4 & 16.7 \\
Progressive disease & 15 & 62.5 \\
Not evaluable & 1 & 4.2 \\
Response rate & & 16.7 \\
\hline
\end{tabular}

Table III. Univariate analysis of clinical factors for ORR of immune checkpoint inhibitors.

\begin{tabular}{lcc}
\hline Clinical factor & ORR (\%) & P-value \\
\hline Age, years & & 0.95 \\
$<75$ & 16.7 & \\
$\geqq 75$ & 17.7 & 0.10 \\
Smoking status & & \\
$\quad$ Smoker & 0 & 0.67 \\
$\quad$ Never & 23.5 & \\
PS & & \\
$0-1$ & 15.8 & 0.10 \\
2 & 25.0 & \\
Resistance gene & & \\
T790M positive & 0 & \\
Negative or unknown & 23.5 & \\
\hline
\end{tabular}

ORR, overall response rate; ICI, immune checkpoint inhibitor; PS, performance status; T790M, EGFR-T790M mutation.

was higher than the numbers reported previously $(14,16)$. Moreover, a subset analysis revealed that patients who had received TKIs for longer term had better PFS than those treated with shorter terms of TKIs (110 vs. 56 days; $\mathrm{P}=0.012$ ). Today, it is a serious clinical problem that there are few treatment choices after standard molecular target therapy. A previous subset analysis of phase III trials of ICIs did not show the OS benefit compared with docetaxel in patients with EGFR mutation $(8,9,11)$. However, because the number of patients included in these studies was small, it has been unclear whether ICIs are effective or not.

Tumor mutation burden (TMB) and PD-L1 are key biomarkers predictive of the effectiveness of ICIs treatment (17). TMB does not correlate with PD-L1 expression and both markers have similar predictive capacity (18). In NSCLC with either EGFR mutation, or ROS-1 or ALK oncogene, TMB is lower than wild type (19-21). This is one of the main reasons why ICIs are less effective for mutant NSCLC. Recently, 80 patients with NSCLC harboring EGFR/ALK mutation were analyzed. The population with PD-L1 tumor proportion score of $50 \%$ or higher was reported to be $11.3 \%$ (22). Several studies showed that PD-L1 expression is also regulated by oncogenic drivers in NSCLC. EGFR

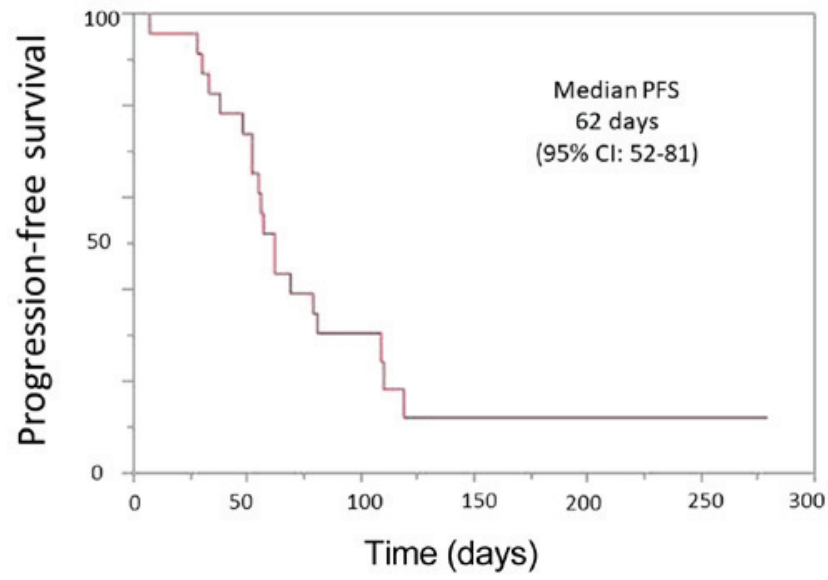

Figure 1. Kaplan-Meier analysis of progression-free survival for all 24 treated patients. The median progression-free survival was 62 days (95\% CI, 52-81). CI, confidence interval.

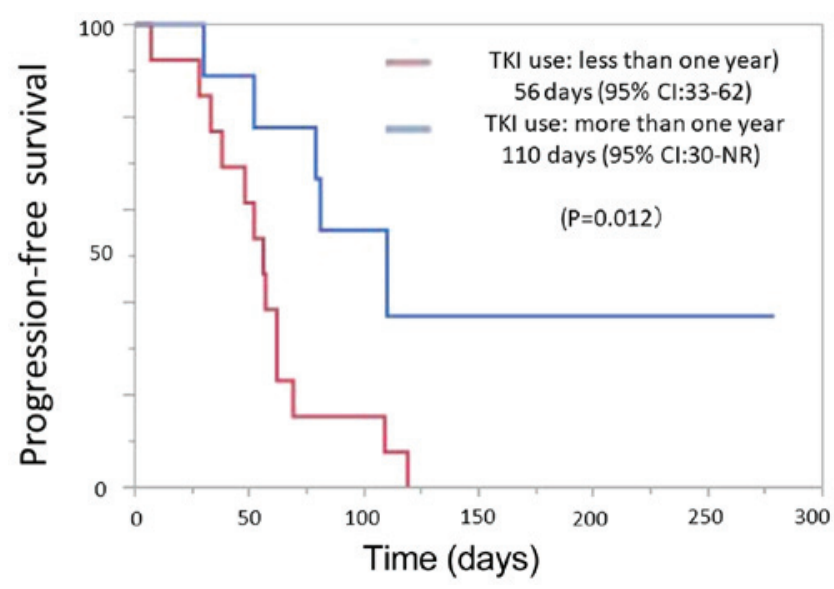

Figure 2. Kaplan-Meier analysis of progression-free survival of patient treated with TKI for $>1$ vs. $<1$ year. A significant difference was observed in the progression-free survival between the patients with longer treatment with TKI and those with shorter treatment (110 vs. 56 days; $\mathrm{P}=0.012$ ). TKI, tyrosine kinase inhibitor.

activated by EGF stimulation, exon 19 deletion and L858R mutation induced PD-L1 expression, suggesting that constitutive oncogene pathway activation can up-regulate PD-L1. Chen and colleagues reported that inhibiting EGFR activation could reduce PD-L1 expression (23). Omori and colleagues showed that treatments with EGFR-TKIs may increase PD-L1 expression in NSCLC harboring EGFR mutations. In that report, 38\% of the patients who were treated with EGFR-TKI increased PD-L1 expression (24). Other research group also suggested PD-L1 expression in tumor cells markedly increased in a subset of patients after gefitinib treatment (25). On the other hand, Lin and colleagues reported that PD-L1 expression did not correlate with treatment response and PFS in EGFR mutant patients, suggesting that PD-L1 status may not be associated with the efficacy of ICIs in patients with driver mutation (26). In our study, PD-L1 expression was not determined in most patients, which is one of the major limitations of our study. In our study, there were no patients who achieved tumor PR in the patients with T790M. Haratani et al reported that T790M-negative patients had longer PFS than T790M-positive 


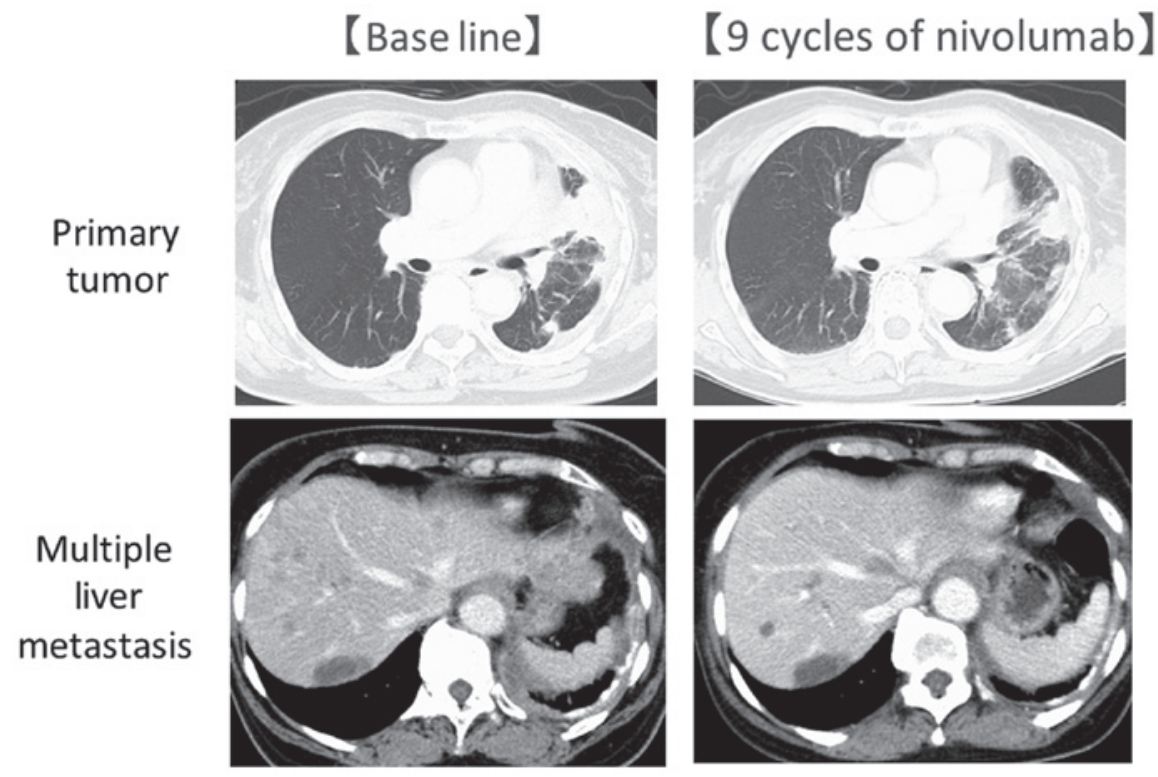

Figure 3. A 71-year old woman was diagnosed with stage IV lung adenocarcinoma with ROS-1 in November 2015. She was treated with nivolumab as second line therapy. After 9 cycles of nivolumab, a computed tomography scan revealed a reduction in size of primary tumor of the left lung and multiple liver metastatic lesions.

patients (2.1 vs. 1.3 months) after EGFR-TKI treatment (27). They suggested that prospective clinical trials are required to confirm the efficacy of PD-1 inhibitors in T790M-negative patients with EGFR mutation-positive NSCLC. Clinical trial is in progress (UMIN000021133). In our study, one patient with ROS-1 was included. The patient had achieved PR. Treatments of ICIs for the patients with rare mutations such as ROS-1, RET has been unclear yet.

Our study had some limitations. First, this study was retrospective study. Second, PD-L1 expression and T790M were not evaluated in every patient. Finally, sample size was small. Further analyses are warranted to determine the efficacy of ICIs in patients with driver mutations after TKI treatment. In conclusion, Even in NSCLC harboring driver mutation, there were some patient who could receive benefit of ICI and the treatment duration of TKI might be related to the efficacy.

\section{Acknowledgements}

Not applicable.

\section{Funding}

No funding was received.

\section{Availability of data and materials}

The datasets used in this current study are available from the corresponding author on reasonable request.

\section{Authors' contributions}

HS prepared the manuscript and made contributions to acquisition of data. HT was invovled in the conception of this study. HT and KT conducted statistical analysis. TS, KB, YI and
MI treated and observed patients in Hirosaki University. YH treated and observed patients in Aomori Prefectural Central Hospital. ShT advised and revised the statistical analysis. SaT contributed in evaluating the tumor efficacy on the CT scan and was a major contributor in writing the manuscript. All authors read and approved the final manuscript.

\section{Ethics approval and consent to participate}

All procedures performed in studies involving human participants were in accordance with the ethical standards of the institutional and/or national research committee and with the 1964 Helsinki declaration and its later amendments or comparable ethical standards. The study protocol was approved by the institutional review boards of all participating institutions.

\section{Patient consent for publication}

The present study was performed on a retrospective observational cohort. Therefore, informed consent was not obtained. The opt out approach was used.

\section{Competing interests}

The authors declare that they have no competing interests.

\section{References}

1. Ettinger DS, Wood DE, Aisner DL, Akerley W, Bauman J, Chirieac LR, D'Amico TA, DeCamp MM, Dilling TJ, Dobelbower M, et al: Non-small cell lung cancer, version 5.2017, NCCN clinical practice guidelines in oncology. J Natl Compr Canc Netw 15: 504-535, 2017.

2. Siegel RL, Miller KD and Jemal A: Cancer statistics, 2017. CA Cancer J Clin 67: 7-30, 2017.

3. Maemondo M, Inoue A, Kobayashi K, Sugawara S, Oizumi S, Isobe H, Gemma A, Harada M, Yoshizawa H, Kinoshita, et al: Gefitinib or chemotherapy for non-small-cell lung cancer with mutated EGFR. N Engl J Med 362: 2380-2388, 2010. 
4. Wu YL, Zhou C, Hu CP, Feng J, Lu S, Huang Y, Li W, Hou M, Shi JH, Lee KY, et al: Afatinib versus cisplatin plus gemcitabine for first-line treatment of Asian patients with advanced non-small-cell lung cancer harbouring EGFR mutations (LUX-Lung 6): An open-label, randomised phase 3 trial. Lancet Oncol 15: 213-222, 2014.

5. Mok TS, Wu Y-L, Ahn MJ, Garassino MC, Kim HR, Ramalingam SS, Shepherd FA, He Y, Akamatsu H, Theelen WS, et al: Osimertinib or platinum-pemetrexed in EGFR T790M-positive lung cancer. N Engl J Med 376: 629-640, 2017.

6. Solomon BJ, Mok T, Kim DW, Wu YL, Nakagawa K, Mekhail T, Felip E, Cappuzzo F, Paolini J, Usari T, et al: First-line crizotinib versus chemotherapy in ALK-positive lung cancer. N Engl J Med 371: 2167-2177, 2014.

7. Shaw AT, Ou SH, Bang YJ, Camidge DR, Solomon BJ, Salgia R, Riely GJ, Varella-Garcia M, Shapiro GI, Costa DB, et al: Crizotinib in ROS1-rearranged non-small-cell lung cancer. N Engl J Med 371: 1963-1971, 2014.

8. Borghaei H, Paz-Ares L, Horn L, Spigel DR, Steins M, Ready NE, Chow LQ, Vokes EE, Felip E, Holgado E, et al: Nivolumab versus docetaxel in advanced nonsquamous non-small-cell lung cancer. N Engl J Med 373: 1627-1639, 2015.

9. Herbst RS, Baas P, Kim DW, Felip E, Pérez-Gracia JL, Han JY, Molina J, Kim JH, Arvis CD, Ahn MJ, et al: Pembrolizumab versus docetaxel for previously treated, PD-L1-positive, advanced non-small-cell lung cancer (KEYNOTE-010): A randomised controlled trial. Lancet 387: 1540-1550, 2016.

10. Reck M, Rodríguez-Abreu D, Robinson AG, Hui R, Csőszi T, Fülöp A, Gottfried M, Peled N, Tafreshi A, Cuffe S, et al: Pembrolizumab versus chemotherapy for PD-L1-positive non-small-cell lung cancer. N Engl J Med 375: 1823-1833, 2016.

11. Rittmeyer A, Barlesi F, Waterkamp D, Park K, Ciardiello F, von Pawel J, Gadgeel SM, Hida T, Kowalski DM, Dols MC, et al: Atezolizumab versus docetaxel in patients with previously treated non-small-cell lung cancer (OAK): A phase 3, open-label, multicentre randomised controlled trial. Lancet 389: 255-265, 2017.

12. Lee CK, Man J, Lord S, Links M, Gebski V, Mok T and Yang JC: Checkpoint inhibitors in metastatic EGFR-mutated non-small cell lung cancer-a meta-analysis. J Thorac Oncol 12: 403-407, 2017.

13. Bylicki O, Paleiron N, Margery J, Guisier F, Vergnenegre A, Robinet G, Auliac JB, Gervais R and Chouaid C: Targeting the PD-1/PD-L1 immune checkpoint in EGFR-Mutated or ALK-Translocated non-small-cell lung cancer. Target Oncol 12: 563-569, 2017.

14. Gainor JF, Shaw AT, Sequist LV, Fu X, Azzoli CG, Piotrowska Z, Huynh TG, Zhao L, Fulton L, Schultz KR, et al: EGFR mutations and ALK rearrangements are associated with low response rates to PD-1 pathway blockade in non-small cel lung cancer: A retrospective analysis. Clin Cancer Res 22: 4585-4593, 2016.

15. Azuma K, Ota K, Kawahara A, Hattori S, Iwama E, Harada T, Matsumoto K, Takayama K, Takamori S, Kage M, et al: Association of PD-L1 overexpression with activating EGFR mutations in surgically resected nonsmall-cell lung cancer. Ann Oncol 25: 1935-1940, 2014
16. Kobayashi K, Nakachi I, Naoki K, Satomi R, Nakamura M, Inoue T, Tateno H, Sakamaki F, Sayama K, Terashima T, et al: Real-world efficacy and safety of nivolumab for advanced non-small-cell lung cancer: A retrospective multicenter analysis. Clin Lung Cancer 19: e349-e358, 2018.

17. Carbone DP, Reck M, Paz-Ares L, Creelan B, Horn L, Steins M, Felip E, van den Heuvel MM, Ciuleanu TE, Badin F, et al: First-line nivolumab in stage IV or recurrent non-small-cell lung cancer. N Engl J Med 376: 2415-2426, 2017.

18. Gandara DR, Paul SM, Kowanetz M, Schleifman E, Zou W, Li Y, Rittmeyer A, Fehrenbacher L, Otto G, Malboeuf C, et al: Blood-based tumor mutational burden as a predictor of clinical benefit in non-small-cell lung cancer patients treated with atezolizumab. Nat Med 24: 1441-1448, 2018.

19. Rozenblum AB, Ilouze M, Dudnik E, Dvir A, Soussan-Gutman L, Geva S and Peled N: Clinical impact of hybrid capture-based next-generation sequencing on changes in treatment decisions in lung cancer. J Thorac Oncol 12: 258-268, 2017.

20. Hatakeyama K, Nagashima T, Urakami K, Ohshima K, Serizawa M, Ohnami S, Shimoda Y, Ohnami S, Maruyama K, Naruoka A, et al: Tumor mutational burden analysis of 2,000 Japanese cancer genomes using whole exome and targeted gene panel sequencing. Biomed Res 39: 159-167, 2018

21. Spiegel DR, Schrock AB, Fabrizio D, Frampton GM, Sun J and He J: Total mutation burden (TMB) in lung cancer (LC) and relationship with response to PD-1/PD-L1 targeted therapies. J Clin Oncol 34 (Suppl 15): S9017, 2016.

22. Yoneshima Y, Ijichi K, Anai S, Ota K, Otsubo K, Iwama E, Tanaka K, Oda Y, Nakanishi Y and Okamoto I: PD-L1 expression in lung adenocarcinoma harboring EGFR mutations or ALK rearrangements. Lung Cancer 118: 36-40, 2018.

23. Chen N, Fang W, Zhan J, Hong S, Tang Y, Kang S, Zhang Y, He X, Zhou T, Qin T, et al: Upregulation of PD-L1 by EGFR activation mediates the immune escape in EGFR-Driven NSCLC: Implication for optional immune targeted therapy for NSCLC Patients with EGFR mutation. J Thorac Oncol 10: 910-923, 2015.

24. Omori S, Kenmotsu H, Abe M, Watanabe R, Sugino T, Kobayashi H, Nakashima K, Wakuda K, Ono A, Taira T, et al: Changes in programmed death ligand 1 expression in non-small cell lung cancer patients who received anticancer treatments. Int J Clin Oncol 23: 1052-1059, 2018.

25. Han JJ, Kim DW, Koh J, Keam B, Kim TM, Jeon YK, Lee SH, Chung DH and Heo DS: Change in PD-L1 expression after acquiring resistance to gefitinib in EGFR-Mutant non-small-cell lung cancer. Clin Lung Cancer 17: 263-270, 2016.

26. Lin SY, Yang CY, Liao BC, Ho CC, Liao WY, Chen KY, Tsai TH, Hsu CL, Hsu WH, Su KY, et al: Tumor PD-L1 expression and clinical outcomes in advanced-stage non-small cell lung cancer patients treated with nivolumab or pembrolizumab: Real-world data in Taiwan. J Cancer 9: 1813-1820, 2018.

27. Haratani K, Hayashi H, Tanaka T, Kaneda H, Togashi Y, Sakai K, Hayashi K, Tomida S, Chiba Y, Yonesaka K, et al: Tumor immune microenvironment and nivolumab efficacy in EGFR mutation-positive non-small-cell lung cancer based on T790M status after disease progression during EGFR-TKI treatment. Ann Oncol 28: 1532-1539, 2017. 